\title{
Futurology of universal health coverage in Iran: A letter to the editor
} Ali Mohammad Mosadeghrad', Mahdiyeh Heydari²

1. Professor of Health Policy and Management, Department of Health Management and Economics, School of Public Health, Health Information Management Research Center, Tehran University of Medical Sciences, Tehran, Iran. ORCID CD: 0000-0002-7955-6292

2. Ph.D Student in Health Care Management, Department of Health Management and Economics, School of Public Health, Tehran University of Medical Sciences, Tehran, Iran, (Corresponding Author), Tel: 021-42933006, Email: m.heydari8994@gmail.com. ORCID CD: 0000-0003-3850-5103

\section{ABSTRACT}

Background and Aim: Universal Health Coverage (UHC) is a strategy for achieving the goal of equity of access to health care for all with preventive, curative and rehabilitative measures and without suffering financial hardship. UHC leads to equitable distribution of health care services, reducing out-of-pocket payments and achieving better health outcome for all people. Some measures have been taken in Iran to achieve UHC. However, the Iranian health system has not yet achieved the goal of UHC.

Material and Methods: The narrative review method was used to write this article.

Results: Implemention of UHC in Iran requires a comprehensive strategic plan. Futurology is the science and art of forecasting, planning, and backcasting. Forecasting is a process which can predict probable future scenarios using trend analysis. Planning is the process of identifying strategies and taking necessary measures to achieve a favorable future. Finally, backcasting allows to identify the opportunities and barriers to achieving the goals.

Conclusion: Futurology can be used to develop a roadmap for UHC in Iran. Awareness of possible future opportunities and risks and taking appropriate measures will help achieve the goal of UHC.

Keywords: Universal health coverage, Iran health system, Futurology

Received: Dec 28, 2019 Accepted: Jan 13, 2021

How to cite the article: Ali Mohammad Mosadeghrad, Mahdiyeh Heydari. Futurology of universal health coverage in Iran: A letter to the editor. SJKU 2021;26(6):1-10.

Copyright (C) 2018 the Author (s). Published by Kurdistan University of Medical Sciences. This is an open access article distributed under the terms of the Creative Commons Attribution-Non Commercial License 4.0 (CCBYNC), where it is permissible to download, share, remix, transform, and buildup the work provided it is properly cited. The work cannot be used commercially without permission from the journal 


\section{آينده يزوهه بوشش همكانى سلامت در ايران: نامه به سردبير}

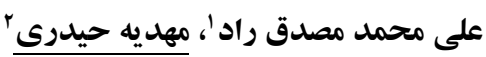

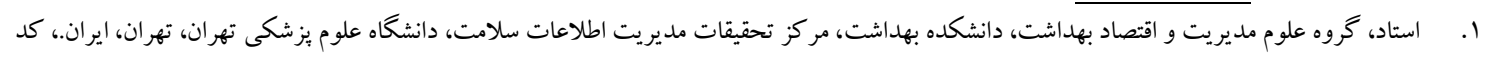

اركيد:

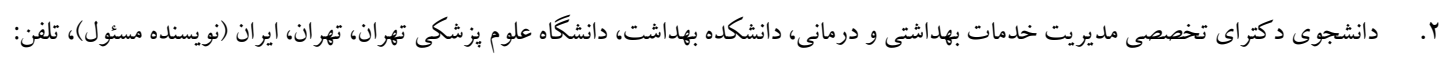

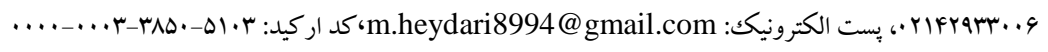

جكيده

زمينه و هدف: يوشش همخانى سلامت، دسترسى همه مردم جامعه به خدمات با كيفيت يشكيرى، درمانى و توانبخشى، به هنكام

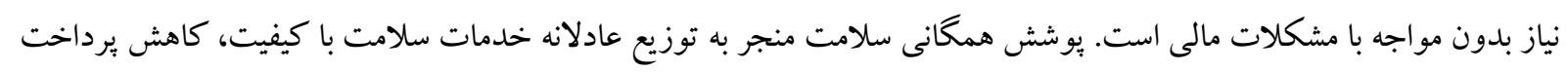

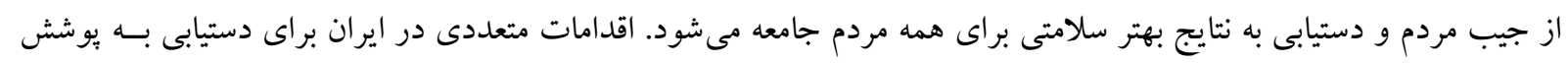

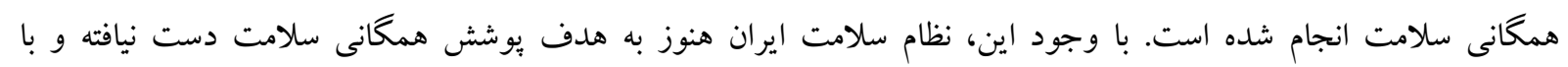
جإلشهايى مواجه است.

مواد و روش ها: براى نوشتن اين نامه به سردبير از روش مرور روايتى استفاده شد.

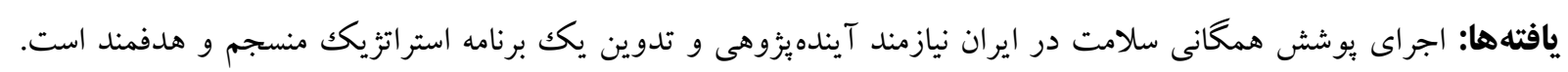

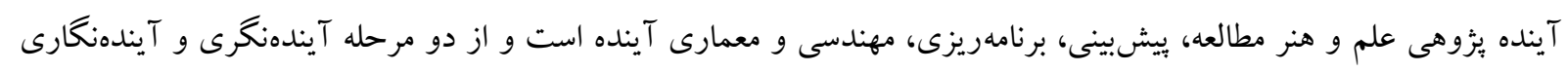

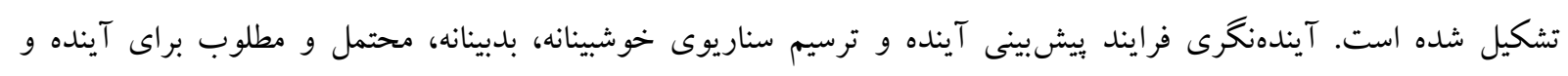

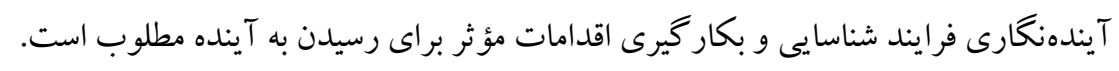

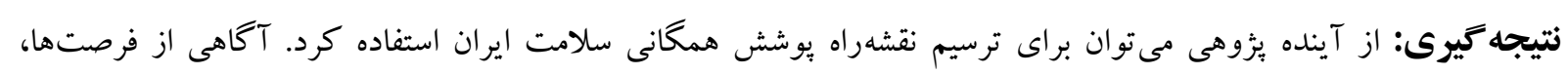

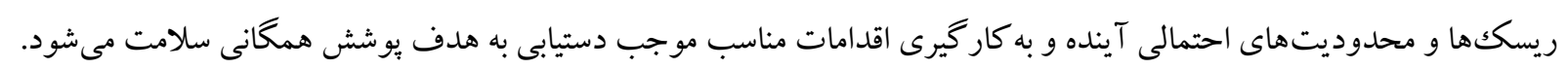

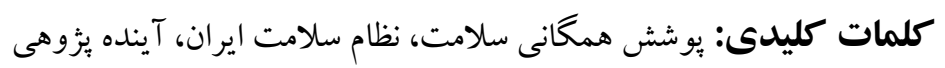


افزايش رشد اقتصادى و حفظ محيط زيست تا سال .r.r. سردبير محترم

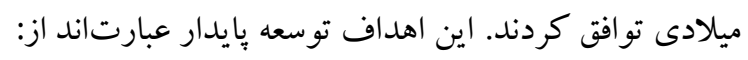

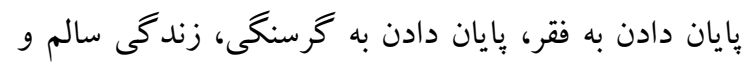

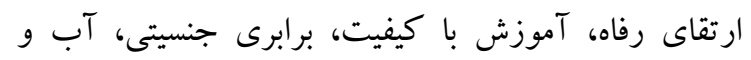

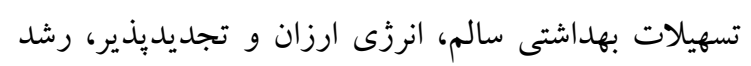
اقتصادى بايدار و مشاغل شايسته، زير ساخت خوب و و توسعه آنه

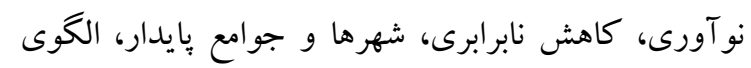
توليد و مصرف مسئولانه، مقابله با تغييرات اقليمى، استفاده وناه

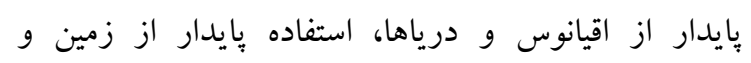

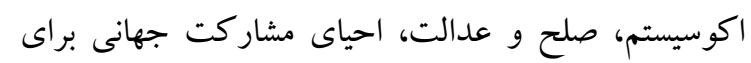
توسعه پيايدار (ه).

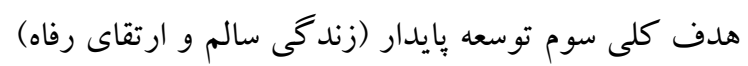

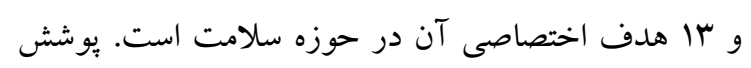

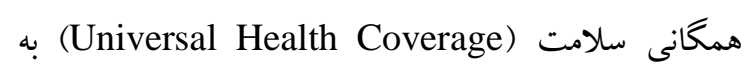
عنوان استراتزى مناسبى براى دستيابى به اهداف نظام سلامت معرفى شده است. يوشش همخانى سلامت، دسترسى همه

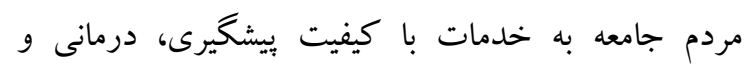

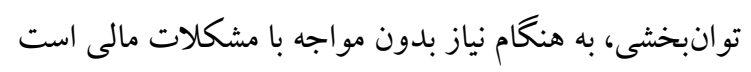

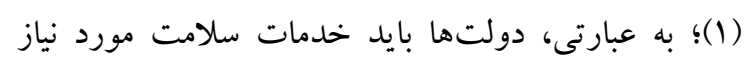
مردم جامعه را بدون اينكه آنها دجار مشكلات مالى دالى شوند، با اجراى يوشش همشانى سلامت فراهم كنند. مكعب يوشش همكانى سلامت شامل ابعاد بوشش جمعيتى Service (Population coverage)

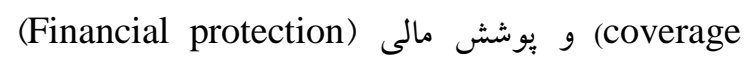

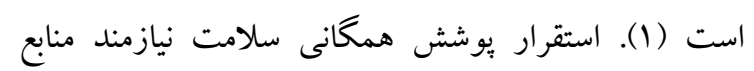
مالى، فيزيكى و انسانى كافى است. كاهش يرداخت مستقيم

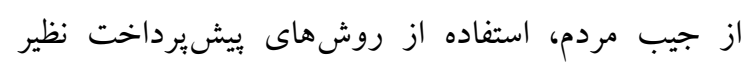

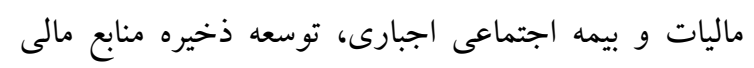

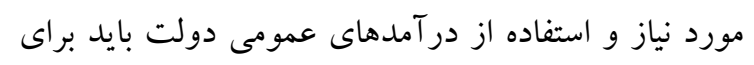
تأمين مالى يوشش همخانى سلامت مورد توجه قرار گيرد.

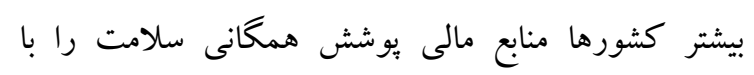
هر انسانى بدون تبعيض نزادى، مذهبى و وضعيت اقتصادى و

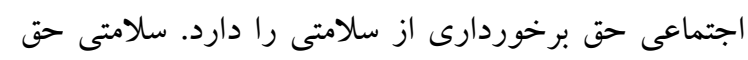

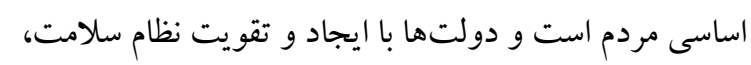
مكلف و موظف به ارائه خدمات سلامت مورد نياز مردم

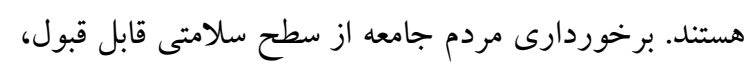

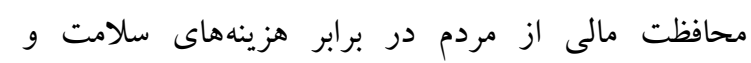

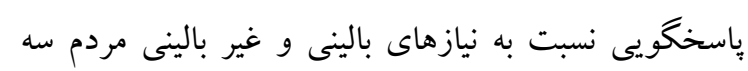

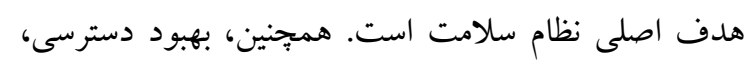

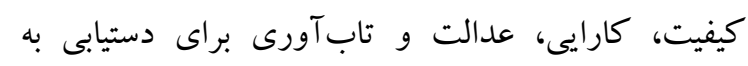
اهداف اصلى نظام سلامت ضرورى است (1).

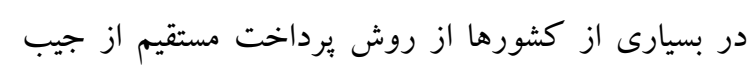

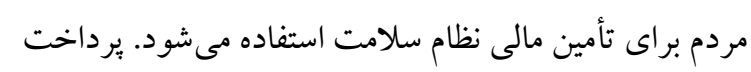

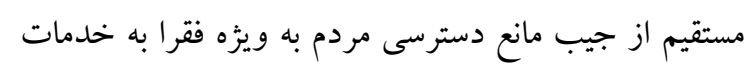

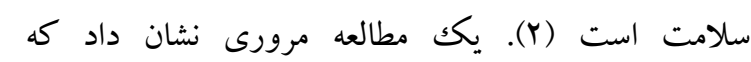
به كار گيرى روش برداخت مستقيم مردم به هنكام دريافت خدمات سلامت منجر به كاهش هـ تا اله درصدى استفاده از

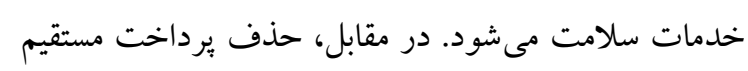

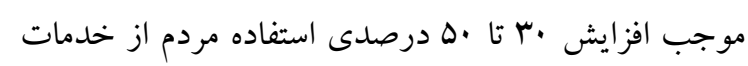
سلامت مى شود (Y). يرداخت مستقيم از جيب مردم زمانى به

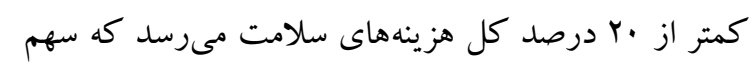

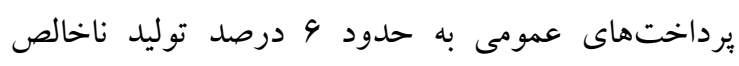

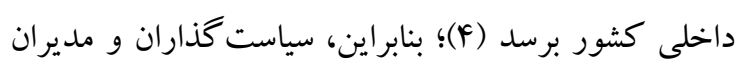
ارشد نظام سلامت بايد تدابيرى براى افزايش دسترسى مردم به خدمات سلامت و كاهش ميزان يُرداخت مستقيم آنها بابت هزينه هاى سلامت اتخاذ كنند.

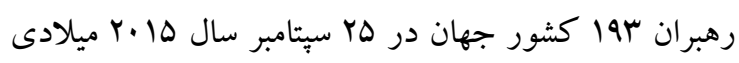

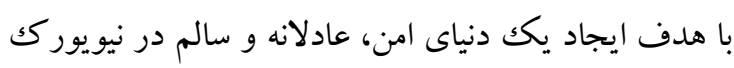

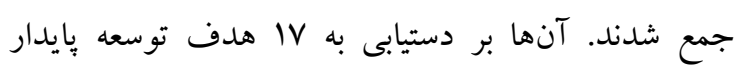
(Sustainable Development Goal) اقتصادى، اجتماعى و محيطى براى حذف فقر و بىعدالتى و هجله علمى دانشكاه علوه يَشكى كردستان / دوره بيست و شش / آذر و دى م.ع|| 
اجراى يوشش همگانى سلامت نيازمند تعهد سياسى دولتها براى ايجاد رفاه اجتماعى براى مردم جامعه است. كشورهاى در حال توسعه با درآمد متوسط و كم با جالشهاى متراى متعددى در زمينههاى توليد و انباشت منابع مالى و ارائه خدمات سلامت براى دستيابى به يوشش همشانى سلامت مواجه

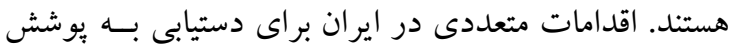
همخانى سلامت انجام شده است. از مهم ترين اين اقدامات

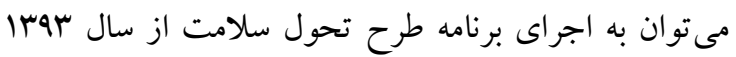

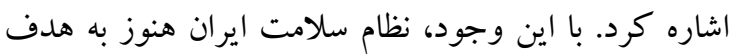

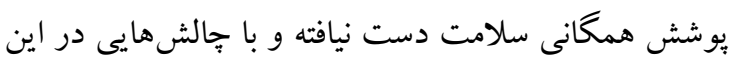

$$
\text { زمينه مواجه است (·) (1). }
$$

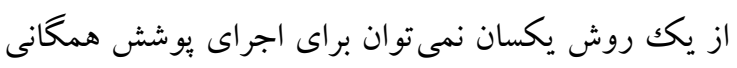
سلامت استفاده كرد. شرايط اجتماعى، اقتصادى، سياسى و

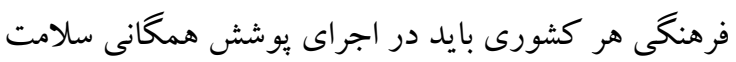

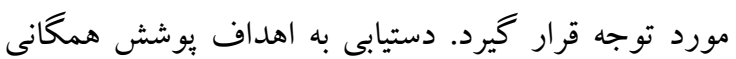

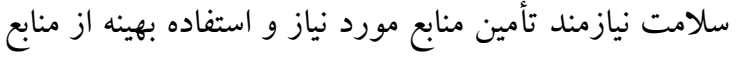
موجود است. اجراى يوشش همكانى سلامت در ايران نيازمند برنامهريزىهاى منسجم و اقدامات هدفمند مؤثر است. آينده يُزوهى يكى از فنون اصلى مديريت و برنامهريزى استراتزيك است كه مىتواند براى ترسيم نقشهراه بوشش همكانى سلامت ايران استفاده شود. آينده قطعى نيست و با تنوع و عدم اطمينان همراه است.

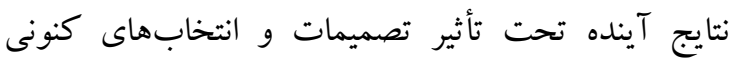
است. به طور كلى، جهار نوع آينده ممكن، موجه، محتمل و مطلوب وجود دارد. آيندههاى ممكن (Possible futures) حالاتى از آينده هستند كه ممكن است اتفاق بيفتند. برخى

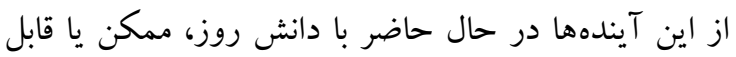

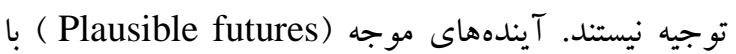
علم روز قابل توجيه هستند و مىتوانند اتفاق بيفتند.

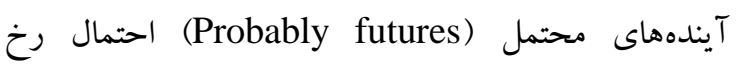
دادنشان با توجه به روندهاى فعلى زياد است. آيندهاى النهاي
استفاده از نظام مالياتى يا بيمه اجتماعى تأمين مى كنند. به

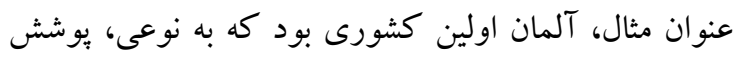

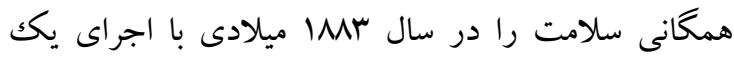

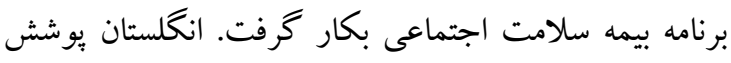

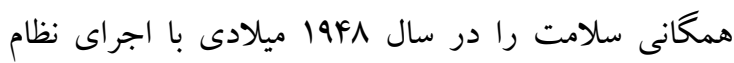
سلامت ملى فراهم نمود.

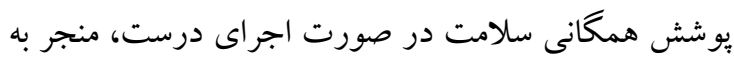
بهبود نتايج سلامتى براى مردم جامعه، كاهش نابرابرى و و

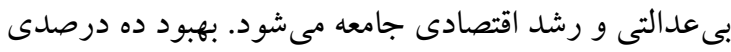

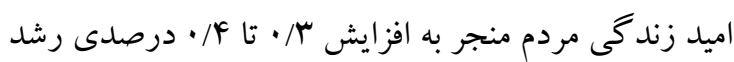
اقتصادى كشور مىشود (9). نظام يوشش همگانى سلامت منجر به توزيع عادلانه خدمات سلامت با كيفيت، كار آمد و

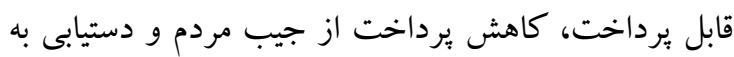
نتايج بهتر سلامتى براى همه مردم جامعه مىشود (V) يوشش همگانى سلامت نه تنها نقش مهمى در دستيابى به

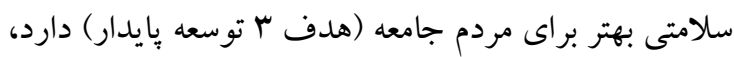

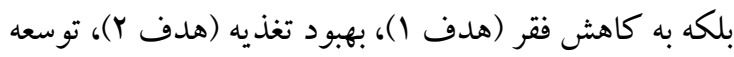
آموزش (هدف F)، برابرى جنسيتى (هدف ه) و توسعه

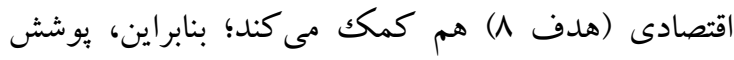

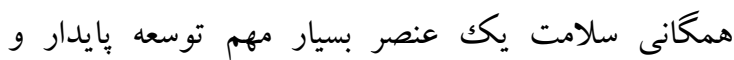
كاهش فقر و بىعدالتى است. دستيابى به هدف مرتبط با سلامت توسعه بايدار (هدف r) از

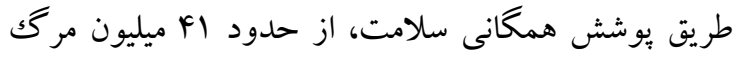

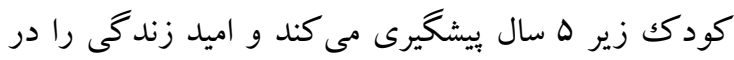
جهان ها سال افزايش مىدهد. سالانه بايد حدود •rV ميليارد دلار آمريكا سرمايهذذارى بيشتر در نظام سلامت براى

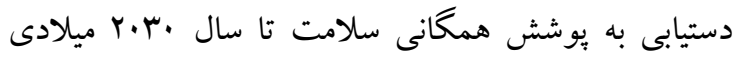

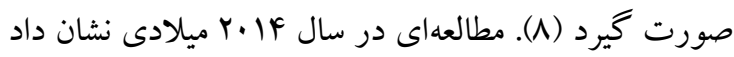
كه كشورها بايد حداقل هـ درصد توليد ناخالص داخلى و يا

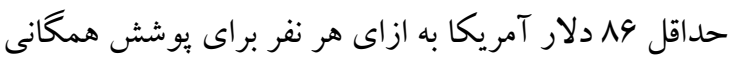
سلامت بكار گيرند (9). 
نظام سلامت شامل سلامتى، محافظت مالى، باسخگگيى،

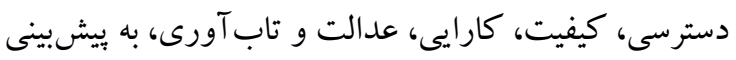

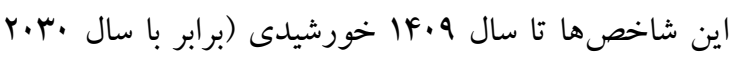
ميلادى) اقدام مى شود. همجنين، روابط علّيتى بين كار كردها

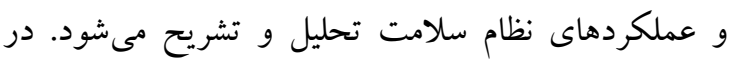
تحليل استراتزيكك محيط خارجى نظام سلامت نيز با استفاده

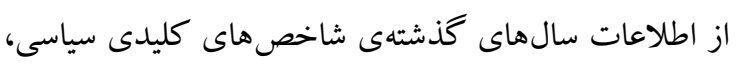
اقتصادى، اجتماعى و فناورى مؤثر بر نظام سلامت، مى توان

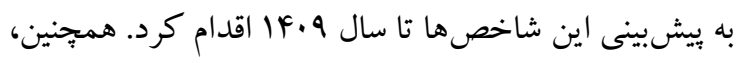

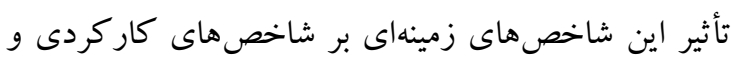
عملكردى نظام سلامت بايد تحليل و تشريح شوند. تحليل

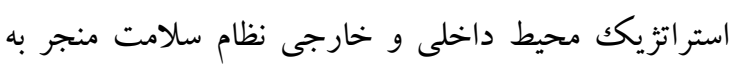
آسيبشناسى اقدامات فعلى برنامه بوشش همشانى سلامت،

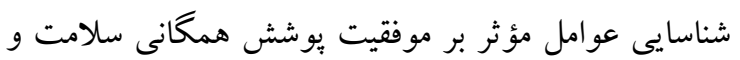

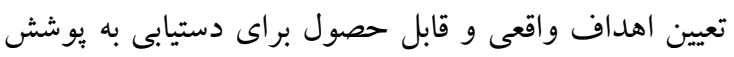

$$
\text { همگًانى سلامت مى شود. }
$$

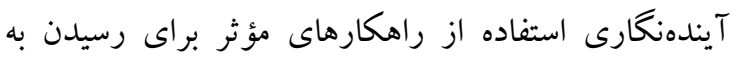
آينده مطلوب است (IF). در اين مرحله سناريوهاى

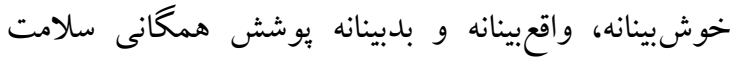

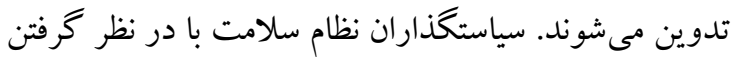
سناريوهاى احتمالى و منابع در دسترس، سناريوى آينده مطلوب ترجيحى را تدوين كرده، اهدافى را براى اين سناريو تعيين و يكك برنامه استراتزيكك براى دستيابى به آنها تدوين مى كنند. در اين مرحله استراتزىها و اقدامات مناسب براى دستيابى به اهداف تعيين شده (آينده مطلوب) شناسايى، ارزشيابى و ييشنهاد مى بـود.
مطلوب (Preferable futures)، نسبت به ساير حالات

آينده، مورد ترجيح سياست گذذاران و مديران هستند (11).

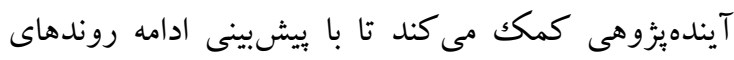
فعلى، از ميزان تحقق اهداف در آينده اطلاع حاصل شوده، بئنس

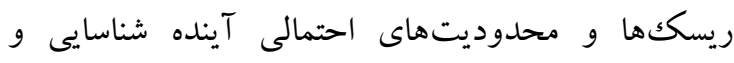

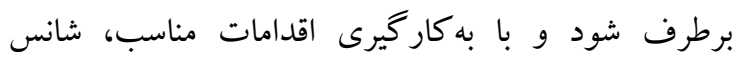
دستيابى به اهداف افزايش يابد و آينده مطلوب حاصل شود.

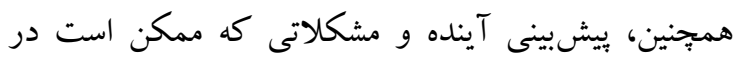

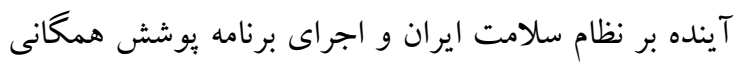

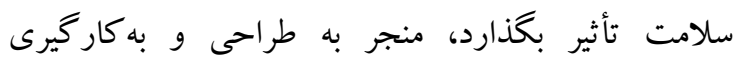
اقداماتى در حال حاضر خواهد شد كه مانع از به وجود بهد

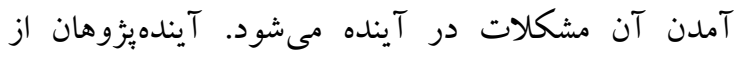

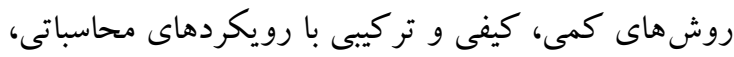
شهودى، تفسيرى و انتقادى براى آينده يُوهى استفاده

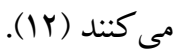
آينده يُزوهى علم و هنر مطالعه، بيشبينى، برنامهريزى،

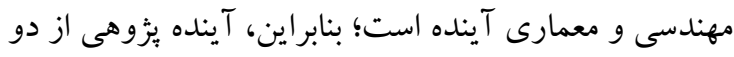

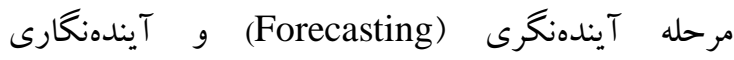
(Foresighting) فر ايند ييشينى آينده با توجه به تحليل روندهاى فعلى است (rا). از فنون تحليل سرى زمانى، تحليل علّيتى و تحليل اثر متقابل مىتوان براى ييشبينى شاخصهاى كاركردى، عملكردى و زمينهاى يوشش همأنى سلامت استفاده كرد. در تحليل استراتزيكك محيط داخلى نظام سلامت، با استفاده

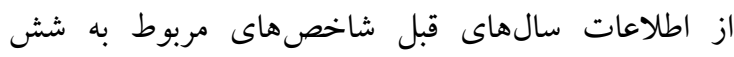
كار كرد اصلى نظام سلامت شامل حاكميت و رهبرى؛ تأمين مالى؛ نيروى انسانى؛ تجهيزات و ملزومات؛ سيستم اطلاعات

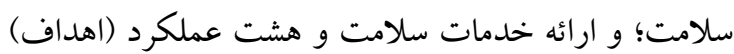

1. World Health Organization. World health statistics 2010, World Health Organization, 2010.

2. World Health Organization. Making fair choices on the path to universal health coverage, World Health Organization, 2014.

هبلم علمى دانشكاه علوه بِرشكى كردستان / دوره بيست و شش / آذر و دى م.عاן 
3. Waiswa WP. The impact of user fees on access to health services in low- and middleincome countries. Geneva: World Health Organization, 2012.

4. McIntyre D, Kutzin J. Revenue collection and pooling arrangements in health system financing. Health systems: a political-economy perspective. 2011.

5. Sachs JD. Achieving the sustainable development goals. JIBE. 2015;8(2):53.

6. Sachs J. Macroeconomics and health: investing in health for economic development. World Health Organization; 2001.

7. McPake B, Hanson K. Managing the public-private mix to achieve universal health coverage. The Lancet. 2016;388(10044):622-30.

8. World Health Organization. Together on the road to universal health coverage: A call to action. World Health Organization; 2017.

9. Jowett M, Brunal MP, Flores G, Cylus J. Spending targets for health: no magic number. World Health Organization; 2016.

10. Mosadeghrad, A.M. Health Transformation Plan in Iran. in J. Braithwaite, W. James, \& K. Ludlow (Eds.) Health Systems Improvement across the Globe: Success Stories from 70 Countries, Taylor \& Francis. 2017: 309-316.

11. Henchey N. Making sense of future studies. Alternatives. 1978;7(2):24-27.

12. Mosadeghrad AM, Mousavi A. The futurology of aging population in Iran: Letter to the Editor. Tehran Univ Med J. 2010;68(3):66-71. [Persian]

13. Mosadeghrad A M, Eslambolchi L. The futurology of normal birth promotion in Iran: letter to editor. Tehran Univ Med J. 2019; 77 (4) :272. [Persian]

14. Mosadeghrad A. Futurology of Iran health transformation plan: letter to the editor. Tehran Univ Med J 2019;77(3):207. [Persian] 